\section{RELIABILITY OF LAMINATED VENEER LUMBER (LVL) BEAMS MANUFACTURED FROM EARLY TO MID-ROTATION SUBTROPICAL HARDWOOD PLANTATION LOGS}

\author{
Benoit P. Gilbert ${ }^{(1)}$, Hao Zhang ${ }^{(2)}$, Henri Bailleres ${ }^{(3)}$ \\ (1) School of Engineering and Built Environment, Griffith University, Australia, b.gilbert@griffith.edu.au (Corresponding \\ author) \\ (2) School of Civil Engineering, The University of Sydney, Australia, hao.zhang@sydney.edu.au

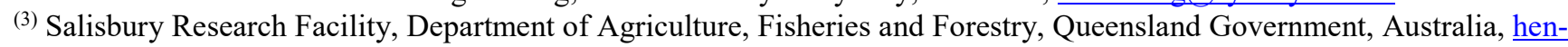 \\ ri.bailleres@daf.qld.gov.au
}

Abstract: This paper presents the reliability analysis of Laminated Veneer Lumber (LVL) beams manufactured from veneers recovered from early to mid-rotation (juvenile) subtropical hardwood plantation logs, with plantations established either for sawn timber applications or pulpwood production. While these logs have a high number of natural defects (knots, gum veins, grain deviation, etc.), are considered of low quality and have little to no commercial value, they produce high strength Veneered Based Composite products, such as Plywood and LVL. Yet, the reliability of these products is unknown. In this paper, the relationship between the reliability index and the capacity factors, also referred to as "resistance factors", used in design equations of such LVL beams in both edge and flat bending is investigated taking into account the load duration effects (damage accumulation). The relationship is presented for six different beam sizes, four grades and three hardwood species (Gympie messmate (Eucalyptus cloeziana), spotted gum (Corymbia citriodora) and southern blue gum (Eucalyptus globulus)) using the strength distribution of the beams recently quantified by the authors. Parametric studies on five main design load combinations stipulated in the Australian standard and three rates of damage accumulation, based on the data available in the literature, are conducted. Results show that the reliability index is highly sensitive to the damage accumulation rate and that the "Dead + Sustained and Extraordinary live loads" and "Dead + Wind + Sustained live loads" load combinations govern the choice of the capacity factor. Recommendations are made on the appropriate capacity factors to be used for various service categories of structures. The proposed capacity factors are found to 
31 be $5 \%$ to $12 \%$ lower than the ones currently used in Australia for the LVL beams manufactured from 32 mature softwood logs, as opposed to juvenile hardwood logs as in the proposed products.

33

34 Keywords: Timber structures; LVL beams; Structural reliability; Probability-based design; Duration 35 of load 


\section{INTRODUCTION}

37 The use of early to mid-rotation (juvenile) hardwood plantation logs in the manufacturing of Veneer Based Composite (VBC) structural products, such as plywood or Laminated Veneer Lumber (LVL), has attracted much attention [1-11]. In Australia, the driving force behind these studies [5-12] lies in (i) the loss opportunities in hardwood plantations grown for high-quality solid timber and their uneconomical long crop rotation time of 30 to 35 years, and (ii) an unfavourable market for woodchips [9] for plantations primarily established for pulpwood production. In the two types of plantation, these juvenile logs are usually harvested 12 to 15 years after establishing the plantation, either in a thinning operation for saw log management regimes (about 30\% of the trees initially planted) or by clear felling products is not viable [6]. However, due to the nature of VBC products that allows the randomisation of the natural defects, plywood and LVL manufactured from these logs make attractive structural products with strengths far superior to the ones of currently commercialised softwood VBC products [1-6]. Yet, published researches only focused on assessing the structural potential of such products but overlooked their reliability aspect for safe structural design purpose. This paper aims at (i) investigating the relationship between the reliability index and the capacity factors, also referred to as "resistance factors", to be used in limit state design of LVL beams manufactured from early to mid-rotation subtropical Gympie messmate (Eucalyptus cloeziana), spotted gum (Corymbia citriodora) and southern blue gum (Eucalyptus globulus) plantation veneers, in both edge bending (i.e. a beam with the veneers in the vertical plane) and flat bending (i.e. a beam with the veneers in the horizontal plane), and (ii) make recommendations on the appropriate capacity factors to be used in the limit state design of such LVL beams. The strength distribution of the products recently quantified in [13-15] is used for this purpose. The analyses are conducted for six different beam sizes, 
mulation) are considered in the study over the assumed 50 years life time of the structure. Five main load combinations (combinations of dead, live and wind loads) specified in the Australian New Zealand Standard AS/NZS 1170.0 [16] and three rates of damage accumulation, based on the data available in the literature, are considered. As only limited areas of Australia are subjected to snow [17], the snow loads are ignored in this study. This paper is the first of its kind to thoroughly assess the reliability of veneer-based products manufactured from juvenile hardwood logs. The outcomes of this paper can be used by standard committees to stipulate appropriate capacity factors so engineers can adopt and safely use the new products. The focus of this paper is on developing the strength limit state design criteria. It should be noted that serviceability limit states such as deflection may govern the design. However, the serviceability limit state is not considered in the present paper.

The paper first presents the stochastic load models and damage accumulation models used in the study. Second, the parametric studies, undertaken herein for five different load combinations, are explained. Third, the results from the parametric studies are presented. Finally, recommendations are made on the softwood logs, as opposed to juvenile hardwood logs as in the proposed products. over the lifetime of the structure are of interest, thus the loads are modelled as random variables, and a first-order reliability method (FORM) can be used for evaluating probability of failure [20]. However, 
and a timber element under a sustained load may fail after a given period of time due to a progressive damage accumulation, also known as creep rupture [21]. Ellingwood et al. [20,22] showed that load damage accumulation must be properly considered through random processes in structural reliability analyses of timber structures, as using a FORM is unsafe and overestimates the reliability index. The time-history of the loads over the entire life span of the building must then be modelled and failure to be predicted using a damage accumulation model [20]. This approach is followed in this paper. It is worth mentioning that the load damage accumulation is classically considered in the Australian timber standard AS 1720.1 [18] through the use of a load duration factors $k$. However, the development of $k$ is not explicitly published in the literature and it is likely [19] that it was not developed through a rigorous structural reliability analysis in which the loads are modelled as stochastic load processes and the duration of load effects rigorously considered.

The following sub-sections detail the stochastic load models and duration of load models used in this study, and the various statistical data considered to develop the probability-based design criterion of the proposed LVL beams. A typical reference period of 50 years is used herein for the life span of timber structures.

\subsection{Load models}

\subsubsection{Dead loads}

The following dead load model $G$ followed in the Australian standards [23] is used herein and given below with associated Coefficient of Variation $(\mathrm{CoV})$ and distribution type:

$$
G \text { : Mean }\left(G_{m}\right) / \operatorname{Nominal}\left(G_{n}\right)=1.05 ; \mathrm{CoV}=0.1 ; \text { Lognormal }
$$

The intensity of the dead load is random; however, it is invariant over the life span of the structure. Thus the dead load is modelled as a random variable.

\subsubsection{Live loads}

Live loads are treated as a stochastic process. Live loads $L$ are broken down into two components in design specifications: (i) a sustained (or "arbitrary point-in-time") component $L_{s}$ representing the live 
113 load due to normal use of the structure (weight of people, furniture, moveable equipment...etc.) and

114 (ii) an extraordinary component $L_{e}$ that simulates shorter events such as crowd gathering, temporary 115 storage during remodelling or emergencies [22].

116 From a stochastic point of view, $L_{s}$ and $L_{e}$ are usually modelled as Poisson processes [24, 25]. Espe117 cially, changes in the intensity of the sustained live load $L_{s}$ occur at a mean rate $v_{s}$ (or mean duration $\tau_{s}$ $\left.118=1 / v_{s}\right)$. The duration of each sustained live load follows an exponential distribution and its intensity a 119 Weibull distribution (Eq. (2)). In the literature, the mean duration, $\tau_{s}$, for the sustained live load ranges 120 from 5 years [26] (based on the Joint Committee on Structural Safety (JCSS) [27] and Conseil Interna121 tional du Batiment (CIB) [28] recommendations for offices) to 8 years [22, 25, 29]. On the other hand, 122 the extraordinary live loads $L_{e}$ occur at a mean rate $v_{e}$ (or a mean time between events $1 / v_{e}$ ) with a 123 short duration $\tau_{e}$. Both the time between events and the event duration follow exponential distributions. 124 In the literature, values of $v_{e}$ and $\tau_{e}$ range between $1 / v_{e}=0.3$ year $/ \tau_{e}=1-3$ days [26] (based on recommendation in [27] for offices), $1 / v_{e}=1$ year $/ \tau_{e}=1-2$ weeks [25], $1 / v_{e}=1$ year $/ \tau_{e}=1$ week [22] and $1 / v_{e}=2$ years $/ \tau_{e}=1$ week [29]. The above leads to the extraordinary live load being applied on average between about 200 days to 700 days over the 50 years live span of a structure. The intensity of the extraordinary live loads typically follows a Gamma distribution [22, 25].

129 It is worth mentioning that in the Australian [18] and European [30] specifications, the extraordinary 130 live loads are considered to be applied over the life time of the structure for five months (152 days) 131 and up to six months (182 days), respectively. This is less or at the bottom range of the recommenda132 tions in the JCSS [27] for office but slightly higher than the recommendations for residence of 50 to 133150 days.

134 Regarding the Australian standards, only the statistics of the overall live load $L$ and sustained live load $135 L_{s}$ over a 50 years period are explicitly reported in the literature [23]. In calibrating the Australian 136 standards, the following were used for a $50 \mathrm{~m}^{2}$ area office floor [31]:

$$
L_{s}: \text { Mean }\left(L_{s m}\right) / \operatorname{Nominal}\left(L_{n}\right)=0.27 ; \mathrm{CoV}=0.72 ; \text { Weibull }
$$


139 The mean occurrence rate for the sustained live load is assumed to be $0.125 /$ year in this study [22, 25]. 140 From $[22,25]$, it is assumed that the mean occurrence rate of the extraordinary live load is $1 /$ year, and 141 the duration $\tau_{e}=1$ week. The intensity of the extraordinary live load has a mean-to-nominal ratio of 142 0.11, and a CoV of 0.60 with a Gamma distribution. This load process model for $L_{e}$, when combined 143 with the sustained live load model in Eq. (2), leads to similar statistics for total live load as given in 144 Eq. (3). Therefore, the following load process model is used for the extraordinary live load in this 145 study:

$$
\begin{aligned}
& \text { Intensity: Mean }\left(L_{e m}\right) / \text { Nominal }\left(L_{n}\right)=0.11 ; \mathrm{CoV}=0.60 \text {, Gamma distribution } \\
& L_{e}: \quad \text { Occurrence: } 1 / v_{e}=1 / \text { year, duration } \tau_{e}=1 \text { week }
\end{aligned}
$$

146 In Eq. (4), the extraordinary live load $L_{e}$ is applied on average for 350 days over the 50 years reference 147 period. This is twice more than the 5 months in the AS 1720.1 [18], but consistent with the literature $148[22,25,29]$ and recommendations in [27].

149 Eqs. $(2,4)$ give a simulated live load model $L$ over a 50 years period closely approaching Eq. (3) of:

$$
L\left(L_{s}+L_{e}\right): \text { Mean }\left(L_{m}\right) / \text { Nominal }\left(L_{n}\right)=0.77 ; \mathrm{CoV}=0.26
$$

151 Figure 1 gives an example of the stochastic live load processes used in this study.

\subsubsection{Wind loads}

153 In reliability analysis of timber structures, the wind is often considered to load the structure in a very short period of time (instantaneous loading) and damage evolution is typically not considered (as further detailed in Section 3.1). As a result, in standard practices a stochastic process is not considered for wind loads and only the distribution of the peak wind load over the 50-year reference period is needed herein. The data provided in [32] are used as the peak wind load $W$ distribution over a 50 years period:

$$
W \text { : Mean }\left(W_{m}\right) / \text { Nominal }\left(W_{n}\right)=0.50 ; \mathrm{CoV}=0.40 ; \text { Type I }
$$

160 [33]. Note that in deriving the capacity factors in the timber Australian Timber Standard AS 1720.1 161 [18], a mean to nominal ratio of 0.33 , with an associated $\mathrm{CoV}$ of 0.39 , seems to have been adopted 
[19]. This distribution would result in higher reliability indexes when compared to the deemed more realistic distribution given in Eq. (6) and used in this study.

\subsection{Duration of load models}

\subsubsection{Models in literature}

Various damage accumulation models [34-37] are reported in the literature to account for the long term strength reduction of timber structural elements relative to the applied load and its duration. While all models are different, they predict a similar time to failure [26, 38, 39], yet this may slightly diverge in estimating the time to failure when failure occurs in the $10^{4}$ to $10^{5}$ hours (1.1 to 11.4 years) range [38]. Due to the relative consistency of all models, only one damage accumulation model is considered in this study and the model developed by Gerhards [34, 35] is used for its simplicity. The evolution of the degree of damage $\alpha$ relative to the time $t$, is given as,

$$
\frac{d \alpha}{d t}=e^{-a+b \frac{f(t)}{f_{0}}}
$$

where $a$ and $b$ are two constants found through experimental tests, $f(\mathrm{t})$ is the stress at time $t$ and $f_{o}$ is the short term strength. $f_{\mathrm{o}}$ is typically determined following international guidelines (such as $[40,41]$ ) from tests loading the structural element to failure in 3 to 5-10 mins. $\alpha=0$ means no damage and $\alpha=1$ means total damage (failure) of the timber element. Values of coefficients $a$ and $b$ for structural lumbers found in the literature at temperature and relative humidity close to the ambient ones are reported in Table 1.

The smaller the values of $a$ and $b$ are, the more sensitive the timber is to creep deformation and the faster the structural element fails under a sustained load. The existing researches on reliability of timber structures typically used values of $a$ and $b$ in the higher range of the ones reported in Table 1 (for instance $a=40 \ln$ (day) and $b=49.75$ in [22, 29, 42], and $a=38.68 \ln$ (day) and $b=46.51$ in [38]). 
and $b$ varying from 26.95 to 68.49 . A difference of 0.5 in the reliability index $\beta$ was observed for Glulam beams between the extreme studied values of $a$ and $b$ for Dead + Live and Dead + Snow load combinations.

\subsubsection{Influence of species and type of structural element}

To the best of authors' knowledge, all experimental tests $[21,35,36,43,44]$ aiming at determining the load duration effect on timber structural members were performed on softwood species and no published data is available so far for hardwood taxa. Creep deformation is correlated to the density (and elastic modulus) of the timber [45, 46] and therefore is likely dependent on the timber species [29, 39]. The load duration behaviour may also be affected by the amount of defects in the juvenile wood and it is not clear how exactly coefficients $a$ and $b$ in Eq. (7) would be affected by the nature of the wood. In international design Specifications [18, 30,47], duration of load is usually accounted for by reducing the allowable strength by a factor $k$ which solely depends on the nature of the load. No distinction is made in coefficient $k$ between wood species (or softwood and hardwood) in these specifications.

The load duration effect is also likely independent on the structural wood product category, i.e. sawn timber or nature of engineered wood products. In Hanhijärvi, et al. [44], no significant differences were observed between the time to failure of two types of engineered wood products (Glulam and LVL beams), both manufactured from spruce wood (Picea abies). Values reported in Table 1 and derived from sawn timber should therefore be applicable to the analysed LVL products.

\subsubsection{Chosen parameters}

Based on the above observations and as the actual values of $a$ and $b$ are unknown for the studied hardwood species, three sets of values are considered in this study:

- Set 1 (Upper values): $a=40.0 \ln ($ day) and $b=49.75$, as used in [20, 22, 38].

- Set 2 (Intermediate values): $a=21.72 \ln ($ day) and $b=26.95$, as used in [25].

- Set 3 (Lower values): $a=16.0 \ln$ (day) and $b=20.0$, as experimentally encountered in [35].

From the experimental observations in $[35,43]$, the ratio between $a$ (in $\ln ($ day)) and $b$ for all loading types and timber moisture content tends to be constant and equal to about $0.80(0.8074$ on average 
with a $\mathrm{CoV}$ of $1.67 \%$ in [35] and 0.7756 on average with a $\mathrm{CoV}$ of $6.6 \%$ in [43]). This ratio is used in

213 the three sets above.

\subsection{Structural resistance}

216 The variation of the Modulus of Rupture (MOR) of LVL beams of six different commercially availa217 ble cross-sectional dimensions (namely (in mm) 200×45, 300×45, 400×45, 240×63, 400×63 and $218600 \times 63)$ and manufactured from early to mid-rotation hardwood logs of three different species (Gym219 pie messmate (Eucalyptus cloeziana), spotted gum (Corymbia citriodora) and southern blue gum (Eu220 calyptus globulus)) were experimentally and numerically analysed in $[13,15]$. The analyses were run 221 for four different grades (qualities) of LVL beams by using either the veneers with "low", "medium" 222 and "high" Modulus of Elasticity (MOE) (see [15] for more details) or all veneers in the manufacturing 223 process. In total 72 statistical distributions of the bending MOR were derived for both edge and flat 224 bending configurations and are fully reported in [13].

225 Results showed that 3-parameters Weibull distributions best fitted the bending MOR distributions. 226 The average mean strength $R_{m}$ to nominal strength $R_{n}$ (taken as the $5^{\text {th }}$ percentile MOR) ratio and asso227 ciated average Coefficient of Variation for the 72 analysed configurations are $R_{m} / R_{n}=1.21$ and $\mathrm{CoV}=$ 2280.11 for edge bending, and $R_{m} / R_{n}=1.33$ and $\mathrm{CoV}=0.16$ for flat bending. On edge bending, the pro229 posed hardwood LVL beams have (i) a lower mean to nominal ratio than softwood LVL beams of $230 \quad 1.36-1.39$ (calculated from Figure 7 in [4]) and (ii) a similar CoV of 0.09 (given by manufacturer [48]) 231 to $0.14-0.16$ (calculated from Figure 7 in [4]).

232 The specific strength distribution of each beam reported in [13] is used in this study, as detailed in Sec233 tion 3.3. 


\subsection{Other parameters}

\subsubsection{Beam dimensions}

237 The required tolerances in the Australian and New-Zealand Standard for LVL structural products 238 (AS/NZS 4357.0 [49]) prevent the dimensions of a cross-section to be less than its nominal dimen239 sions. Beams with a cross-section larger than the nominal one will experience higher bending strength 240 than the nominal one and conservatively, the manufacturing tolerances on the cross-sectional dimen241 sions are not considered in the study. The dimensions of a cross-section are therefore taken as its nom242 inal values.

\subsubsection{Model uncertainties}

244 The distributions of the bending MOR of the LVL beams obtained through experimental studies and 245 numerical analyses in $[13,15]$ consider the uncertainties in the numerical model used, i.e. the discrep246 ancy between the actual beam capacity and the predicted one. Therefore, no further correction is need247 ed herein to take into account these uncertainties.

\subsubsection{Moisture content}

249 While the damage accumulation is sensitive to the timber moisture content [43, 44], the LVL beams 250 are assumed to be used in an indoor environment where changes in temperature and relative humidity 251 are limited. No modification of the coefficients of the damage accumulation model is considered to 252 taken into the variation of moisture content in the timber. This approach is similar to the ones reported 253 in the literature, e.g. [22, 50, 51].

\section{PROBABILITY-BASED DESIGN AND PARAMETRIC STUDIES}

\subsection{Load combinations}

257 In timber structural design specifications based on probability-based limit-states design (PBLSD), the 258 following load and resistance factor design (LRFD) check needs to be performed:

$$
k \phi R_{n} \geq \sum \gamma_{i} Q_{n i}
$$


where $\phi$ is the capacity factor that accounts for the uncertainties in structural strength, $k$ is the load du-

261 ration factor which depends on the duration of the load combination of interest and is given in design 262 Specifications, $R_{n}$ is the nominal structural strength, $Q_{n i}$ are the load effects and $\gamma_{i}$ are the load factors.

263 The following five main LRFD load combinations given in the Australian New Zealand standard 264 AS/NZS $1170.0[16]$ are considered in this paper:

- $L C 1: 1.35 G_{n}$ (Dead loads only) and $k=0.57$

- $\quad L C 2: 1.2 G_{n}+1.5 L_{n}($ Dead + Sustained and Extraordinary live loads) and $k=0.80$

- $L C 3: 1.2 G_{n}+1.5 \times 0.4 L_{n}($ Dead + Sustained live loads $)$ and $k=0.57$

- LC4: $1.2 G_{n}+W_{n}+0.4 L_{n}($ Dead + Wind + Sustained live loads $)$ and $k=1.00$

- LC5: $W_{n}-0.9 G_{n}($ Dead + Wind reversal $)$ and $k=1.00$

The above values of $k$ are recommended values in Appendix G of the Australian Timber Standard AS 1720.1 [18]. Note that LC3 never governs the design for $L_{n} / G_{n}$ ratios encountered in timber structures (typically $L_{n} / G_{n}=3[52]$ ) and the reliability of this load case is investigated in this study for information only. Additionally, the dead and wind reversal load combination (LC5) usually governs the design of the connections, not the members, but is still analysed herein.

Stochastic load processes are only considered herein for LC1 to LC3 based on best practices in the literature $[20,22,25,26,29,42,51]$. As the wind only loads a structure for a short period of time, load damage accumulation due to wind loading is usually ignored in reliability analyses of timber structures, such as in [53]. A first-order reliability method in which the loads are modelled as random variables is then used herein for LC4 and LC5.

\subsection{Parametric studies}

282 For timber structures, the ratio $L_{n} / G_{n}$ is typically of the order of 3 and $W_{n} / G_{n}$ in the range of 1 to 4 [52]. 283 In this paper, Monte Carlo simulations are run for both ratios $L_{n} / G_{n}$ and $W_{n} / G_{n}$ varying from 1 to 4 , in 0.5 increments. The simulations are also run for every single beam configuration analysed in [13] (i.e. 
beam size and grade as given in Section 2.3) and the variation of the reliability index $\beta$ is statistically reported for all 72 analysed beam configurations in [13]. Per investigated configuration, $10^{6}$ Monte Carlo simulations are run.

The reliability index $\beta$ for each configuration is calculated as [54],

$$
\beta=-\Phi^{-1}\left(P_{f}\right)
$$

where $\Phi$ is the cumulative distribution function of the standard normal variable and $P_{f}$ is the probability of failure obtained from $10^{6}$ Monte Carlo simulations. Failure occurs when (i) for LC1 to LC3, the degree of damage $\alpha$ calculated from the randomly generated applied loads (Section 2.1) and structural resistance (Section 2.3) is equal to 1.0 within the 50 years period considered, and (ii) for LC4 and LC5, the randomly generated applied loads (Section 2.1) are greater than the randomly generated structural resistance (Section 2.3).

To best determine the relationship between the reliability index $\beta$ and the bending capacity factor $\phi$ of the new timber products, Monte Carlo simulations are run for values of $\phi$ in Eq. (8) ranging from 0.7 to 0.95 , typically in 0.5 increments. If all targeted reliability indices given in following Section 3.3 were not reached for at least one of the load damage accumulation set in Section 2.2, the simulations were extended to lower values of $\phi$.

\subsection{Target reliability indices}

The Australian standard on timber structures AS 1720.1 [18] has three different service categories of structures, depending on their importance level. Category 1 is for houses and secondary structures,

Category 2 for primary structural members other than houses and Category 3 for "primary structural members in structures intended to fulfil an essential service or post disaster function". For LVL beams, no distinction is made between edge and flat bending and the capacity factor $\phi$ is equal to $0.95,0.90$ and 0.80 for structural members in Categories 1,2 and 3 , respectively.

While the actual target reliability indices $\beta_{T}$ used in calibrating the AS 1720.1 [18] are not explicitly published, reference can be made to the Australian standard AS 5104 [55] which provides the general 
311 principles on reliability of structures. Assuming a "moderate" relative costs of safety measures, Table 312 E2 in the AS 5104 [55] gives life-time targeted reliability indices $\beta_{T}$ for Categories 1, 2 and 3 in the AS 3131720.1 [18] of $2.3,3.1$ and 3.8, respectively. These targets are used in the study for LC1 to LC3. How314 ever, the reliability index when designing for wind load is historically lower than when designing for 315 gravity load $[52,56]$. While, this is a subject of contestation [56], a target reliability index of 2.5 [52] 316 for all service categories is used in the study for LC4 and LC5.

317 For comparison purposes, the North American specification [57] does not consider service classes and 318 has a capacity factor $\phi=0.85$ for LVL beams, while the Eurocode 5 [30] considers service classes but 319 through different load duration factors $k$, not through adjusting the value of the capacity factor as in the AS 1720.1 [18]. For LVL beams, $\phi=1 / 1.2 \approx 0.83$ in the Eurocode 5 [30].

\section{RESULTS AND DISCUSSION}

\subsection{Dead loads only (LC1)}

324 Figure 2 shows the evolution of the reliability index $\beta$ versus the capacity factor $\phi$ for LC1, all sets of load damage accumulation values and flat and edge bending. The variation in reliability index for all studied beam configurations (sizes, grades and species) is shown in Figure 2 with box plots. The continuous line represents the average reliability index of all beam configurations.

Due to the larger variability in the bending capacity of beams tested on flat bending compared to edge bending (See Section 2.3 and [13]), the reliability index for flat bending is typically lower than for edge bending. This is more pronounced for load damage accumulation Sets 1 and 2 than for Set 3. Additionally, a large influence of the values of $a$ and $b$ used in the load damage accumulation model on the reliability index can be observed in Figure 2. This influence is more significant than the one encountered by Hendrickson et al. [25], likely because of the difference in the structural resistance $R_{m} / R_{n}$ ratios used in the two studies, with $R_{m} / R_{n}=2.59$ in [25] and $R_{m} / R_{n}=1.21-1.33$ herein (see Section 2.3). 
- For Set 1, the current capacity factors $\phi$ of $0.95,0.90$ and 0.80 used in the AS 1720.1 [18] for structural members in Categories 1, 2 and 3, respectively, are adequate for edge bending. For flat bending, the capacity factor for structural members in Category 3 would have to be reduced to 0.75 to meet an average reliability index of 3.8 .

- For Set $2(a=21.72 \ln ($ day $)$ and $b=26.95)$ and edge bending, using capacity factors $\phi$ of $0.80,0.70$ and 0.65 would meet the targeted reliability indices for structural members in Categories 1, 2 and 3, respectively. For flat bending, capacity factors $\phi$ of 0.75 and 0.65 meet the targeted reliability index for structural members in Categories 1 and 2, respectively. For structural members in Category 3,

- For Set $3(a=16.0 \ln ($ day $)$ and $b=20.0)$ and all cases, the minimum targeted reliability index $\beta_{T}=$ 2.3 for structural members in Category 1 cannot be achieved, with the highest average reliability in$\operatorname{dex} \beta=2.1$ found for $\phi=0.60$ and flat bending.

The variability in $\beta$ between investigated beam configurations is typically more pronounced for beams bent on flat than for beams bent on edge, with variability in $\beta$ of the latter being about $+/-0.5$.

\subsection{Dead and Live loads (LC2 and LC3)}

\subsubsection{LC2 (Dead + Sustained and Extraordinary live loads)}

Figure 3 (a-c) plots the variation of the average reliability index $\beta$ for LC2 of all beam configurations

for flat bending and all sets of load damage accumulation values, studied ranges of capacity factors $\phi$ and Live to Dead ratios $L_{n} / G_{n}$. To apprehend the variability between all studied beam configurations, the variability in reliability index $\beta$ is plotted for selected cases in the form of box plots in Figure 3 (d). Figure 4 plots the same as Figure 3 but for edge bending.

358 The reliability index $\beta$ increases with increasing values of $L_{n} / G_{n}$ for all cases but edge bending and 359 load damage accumulation Set 1 . This increasing rate is more pronounced for low values of $L_{n} / G_{n}$ and decreasing load damage accumulation values $a$ and $b$.

361 From the average reliability index $\beta$ in Figure 3 and Figure 4, the following observations can be made: 
- For Set 1 and realistic values of $L_{n} / G_{n}$ of 2 to 4 [52], the following applies: (i) the variation in $\beta$ is

363 marginal and less than 0.1 , (ii) for edge bending the capacity factors $\phi$ used in the AS 1720.1 [18] 364 are adequate to achieve the targeted reliability indices for all categories of structural members, (iii) 365 for flat bending, only the capacity factor $\phi=0.95$ in the AS 1720.1 [18] is adequate to achieve the 366 targeted reliability index $\beta_{T}=2.3$ for structural members in Category 1 , and (iv) for the other cate367 gories on flat bending, capacity factors $\phi$ of 0.80 and 0.70 would satisfy the targeted reliability indi368 ces for structural members in Categories 2 and 3, respectively.

- For Set 2, Figure 3 and Figure 4 show that: (i) for flat bending, capacity factors $\phi$ of 0.90 and 0.70 370 would satisfy the targeted reliability indices for structural members in Categories 1 and 2, respectively, (ii) for edge bending, capacity factors $\phi$ of 0.90 and 0.75 would satisfy the targeted reliability indices for structural members in Categories 1 and 2, respectively, and (ii) a capacity factor $\phi$ lower than 0.70 would be required to achieve the safety level required for structural members in Category 3.

- For Set 3, the minimum targeted reliability index $\beta_{T}=2.3$ for structural members in Category 1 is only achieved for $\phi=0.7$ and $L_{n} / G_{n} \geq 2.5$, for both flat and edge bending.

377 Similar to LC1, the variability in $\beta$ between investigated beam configurations is typically more pro378 nounced for flat than edge bending.

\subsubsection{LC3 (Dead + Sustained live loads)}

380 Figure 5 and Figure 6 plot the same as Figure 3 and Figure 4 but for LC3. An opposite relationship to 381 LC2 can be observed for LC3 in Figure 5 and Figure 6, with the reliability index $\beta$ decreasing with in382 creasing values of $L_{n} / G_{n}$, especially for load damage accumulation Sets 1 and 2. For Set 1 and realistic 383 values of $L_{n} / G_{n}$ of 2 to 4 [52], the variation in $\beta$ is maximum and about 0.4-0.5.

384 The following observations can be made from the average reliability index $\beta$ presented in Figure 5 and 385 Figure 6: 
- The reliability indices achieved for LC3 are significantly lower than for LC2, with the targeted reliability index $\beta_{T}=3.8$ for structural members in Category 3 only reached for load damage accumulation Set 1 when $\phi \geq 0.70$ and $\geq 0.60$ for edge and flat bending, respectively.

- For Set 1 and edge bending, capacity factors $\phi$ of $0.85,0.70$ and 0.60 would typically satisfy the targeted reliability indices for structural members in Categories 1,2 and 3 respectively. For flat bending, capacity factors $\phi$ of 0.85 and 0.65 would satisfy the targeted reliability indices for structural members in Category 1 and 2, respectively. However for Categories 3, capacity factors $\phi$ lower than 0.60 must be used.

- For Set 2 and edge bending, capacity factors $\phi$ lower than 0.60 and $0.65-0.70$ would satisfy the targeted reliability indices for structural members in Category 1 and 2, respectively. For flat bending and the studied range of $\phi$, only the targeted reliability index $\beta_{T}=2.3$ for structural members in Category 1 can be achieved for $\phi=0.65$.

- For Set 3 and the studied range of $\phi$, the reliability index $\beta$ is typically lower than the three targeted indices $\beta_{T}$ for the range of realistic values of $L_{n} / G_{n}$ of 2 to 4 .

\subsection{Dead, Wind and Live loads (LC4)}

Figure 7 (flat bending) and Figure 8 (edge bending) plots the variation of the average reliability index $\beta$ of all beam configurations versus the studied ranges of Live to Dead ratios $L_{n} / G_{n}$ and Wind to Dead ratios $W_{n} / G_{n}$ for selected capacity factors $\phi$ of $0.60,0.70,0.80$ and 0.90 . It is worth reminding that as LC4 is not modelled as a stochastic load process (see Section 3.1) no load accumulation effect is considered.

The following observations can be made from the average reliability index $\beta$ reported in Figure 7:

- For both edge and flat bending, the reliability index $\beta$ is maximum for $L_{n} / G_{n}=W_{n} / G_{n}=1$ and minimum for $L_{n} / G_{n}=4$ and $W_{n} / G_{n}=1$. The higher the $W_{n} / G_{n}$ ratio is, the less the value of the $L_{n} / G_{n}$ ratio influences $\beta$. 
- For both flat and edge bending and realistic values of $L_{n} / G_{n}$ of 2 to 4 and $W_{n} / G_{n}$ of 1 to 4 [52], a capacity factor $\phi$ of $0.80-0.85$ would meet for the targeted reliability index $\beta_{T}$ of 2.5 .

\subsection{Dead and Wind reversal (LC5)}

415 Figure 9 plots the variation of the average reliability index $\beta$ of all beam configurations versus the 416 Wind to Dead ratio $W_{n} / G_{n}$ and for selected capacity factors $\phi(0.60,0.70,0.80$ and 0.90$)$.

417 The following observations can be made from the average reliability index $\beta$ reported in Figure 9:

- The reliability index $\beta$ is similar for both edge and flat bending and increases with $W_{n} / G_{n}$.

- The influence of the choice of the capacity factor $\phi$ is more pronounced for higher values of $W_{n} / G_{n}$.

- For both flat and edge bending, the reliability index $\beta$ is only below the targeted reliability index $\beta_{T}$ of 2.5 for $W_{n} / G_{n}=1$ and the capacity factor $\phi$ of $0.80-0.85$ proposed for LC4 would therefore be typically satisfactory for LC5.

\subsection{Recommendations}

Load duration factors $k$ used in international design Specifications are usually derived from the classical "Madison" curve [21, 25]. This curve provides similar load duration factors (within 2.5\%) to load accumulation Set 1, for load duration greater than 5 days. Moreover and as the Australian standard AS 1720.1 [18] does not consider differences between wood species in its reliability framework, recommendations on appropriate capacity factors $\phi$ to be used to design the proposed LVL beams are made in this section solely based on results derived from load damage accumulation Set 1 . This will result in 431 the proposed beams having a similar level of safety to the ones currently commercialised, and there432 fore not disadvantaging them on the marketplace. However, there is a need to assess the actual load 433 duration effects of the proposed beams.

434 As discussed in Section 3.1, LC3 does not govern the design and is disregarded herein in the recom- 
typically govern the choice of the capacity factor. Table 2 gives the proposed $\phi$ factors for all structural member categories in the AS 1720.1 [18] following the observations presented in the paper. Contrary to international design specifications $[16,30,57]$, where no difference is made between edge and flat bending in the choice of $\phi$, two sets of capacity factors are proposed herein due the different edge and flat bending strength distributions.

441 The reliability factors of the proposed LVL products are 5\% to $12 \%$ lower than the ones specified in the Australian standard AS 1720.1 [18] for commercialised LVL beams (typically manufactured from mature softwood logs). However and as mentioned earlier, they are differences between the reliability approach in this study and the AS 1720.1 [18]: (i) stochastic load processes combined with a proper load damage accumulation model were likely not considered in the calibration of the AS 1720.1 and (ii) a different mean to nominal ratio was also likely used for the wind load. Ellingwood et al. [20, 22] showed that the former approach is unsafe and overestimates the reliability index $\beta$. The difference in the reliability factors between the present study and the AS 1720.1 may therefore be less significant if similar reliability analysis frameworks were adopted. Further investigations are needed to evaluate this difference. Additionally, the mean-to-nominal ratio for LVL beams used in the calibration of the AS 1720.1 is not available and may be different to the ones used in this paper.

\section{CONCLUSION}

454 This paper presented the relationship between the reliability index $\beta$ and the capacity factor $\phi$ for LVL beams manufactured from early to mid-rotation subtropical hardwood plantation logs. Five main load combinations in the Australian New Zealand standard AS/NZS 1170.0 [16] were investigated. Stochastic load processes and three sets of load damage accumulation were considered. Results show that

458 for the proposed beams, the value of the load accumulation parameters greatly influences the reliability index. The "Dead + Sustained and Extraordinary Live Loads" and "Dead + Wind + Sustained Live Loads" load combinations were found to typically govern the choice of the capacity factor. For edge 461 bending, capacity factors of $0.85,0.85$ and 0.80 are recommended for the proposed hardwood beams 
and structural members in Categories (service class) in the Australian standard AS 1720.1 [18] of 1, 2 and 3, respectively. Capacity factors of $0.85,0.80$ and 0.70 are recommended on flat bending for structural members in Categories 1, 2 and 3, respectively.

\section{ACKNOWLEDGMENT}

467 The authors would like to thank the Australian Research Council for its financial contribution under 468 project DE140100212.

\section{REFERENCES}

[1] B. Ozarska "A review of the utilisation of hardwoods for LVL", Wood Science and Technology, 33, 341-351, 1999.

[2] B.C. Bal, I. Bektaş "The effects of wood species, load direction, and adhesives on bending properties of laminated veneer lumber", BioRessources, 7, 3104-3112, 2012.

[3] J. Saviana, M.A. Sosa Zitto, J.C. Piter "Bending strength and stiffness of structural laminated veneer lumber manufactured from fast-growing Argentinean Eucalyptus grandis", Maderas. Ciencia y tecnología, 11, 183-190, 2009.

[4] D. Gaunt, B. Penellum, H.M. McKenzie "Eucalyptus nitens laminated veneer lumber structural properties", New Zealand Journal of Forestry Science, 33, 114-125, 2002.

[5] R.L. McGavin, H. Bailleres, F. Lane, J. Fehrmann, High value timber composite panels from 481 hardwood plantation thinnings, Department of Agriculture, Fisheries and Forestry, Brisbane, Australia, 4822013.

483 [6] R.L. McGavin, M.P. Davies, J. Macgregor-Skinner, H. Bailleres, M. Armstrong, W.J. Atyeo, J. 484 Norton, Utilisation potential and market opportunities for plantation hardwood thinnings from 485 queensland and northern New South Wales, PN05.2022, Department of Primary Industry and 486 Fisheries, Queensland Government, Brisbane, Australia, 2006. 
487 [7] R.L. McGavin, H. Bailleres, J. Fehrmann, B. Ozarska "Stiffness and Density Analysis of Rotary 488 Veneer Recovered from Six Species of Australian Plantation Hardwoods", BioRessources, 10, 6395$4896416,2015$.

490 [8] R.L. McGavin, H. Bailleres, F. Lane, D. Blackburn, M. Vega, B. Ozarska "Veneer Recovery 491 Analysis of Plantation Eucalypt Species Using Spindleless Lathe Technology", BioRessources, 9, 613$492627,2014$.

493 [9] R.L. McGavin, H. Bailleres, F. Lane, J. Fehrmann, B. Ozarska "Veneer Grade Analysis of Early to 494 Mid-rotation Plantation Eucalyptus Species in Australia", BioRessources, 9, 6562-6581, 2014.

495 [10] B.P. Gilbert, I.D. Underhill, H. Bailleres, A. El Hanandeh, R.L. McGavin "Veneer Based 496 Composite hollow utility poles manufactured from hardwood plantation thinned trees", Construction 497 and Building Materials, 66, 458-466, 2014.

498 [11] H. Lu, A. El Hanandeh "Environmental and economic assessment of utility poles using life cycle 499 approach", Clean Technologies and Environmental Policy, DOI 10.1007/s10098-10016-11299-10094, 5002016.

501 [12] B.P. Gilbert, I.D. Underhill, D. Fernando, H. Bailleres "Structural solutions to produce long 502 timber Veneer Based Composite hollow sections", Construction and Building Materials, 139, 81-92, 5032017.

504 [13] B.P. Gilbert, H. Bailleres, H. Zhang, R.L. McGavin "Strength modelling of Laminated Veneer 505 Lumber (LVL) beams", Construction and Building Materials, 149, 763-777, 2017.

506 [14] B.P. Gilbert "Compressive strength prediction of veneer-based structural products", ASCE 507 Journal of Materials in Civil Engineering (Accepted), 2018.

508 [15] B.P. Gilbert, H. Bailleres, M.F. Fischer, H. Zhang, R.L. McGavin "Mechanical properties of 509 rotary veneers recovered from early to midrotation subtropical-hardwood plantation logs for veneer510 based composite applications.", ASCE Journal of Materials in Civil Engineering, 29, 04017194, 2017.

511 [16] AS/NZS 1170.0, Structural design actions, Part 0: General principles, Standards Australia, 512 Sydney, Australia, 2002. 
513 [17] AS/NZS 1170.3, Structural design actions, Part 3: Snow and ice actions, Standards Australia, 514 Sydney, Australia, 2003.

515 [18] AS 1720.1, Timber structures, Part 1: Design methods, Standards Australia, Sydney, Australia, 5162010.

517 [19] L. Pham, J. Carson "Derivation of equations for determination of capacity factors (report prepared 518 for SAI TC TM001/WG)", Non published, 2007.

519 [20] B.R. Ellingwood "Probability-based LRFD for engineered wood construction", Structural Safety, $520 \quad 19,53-65,1997$.

521 [21] L.W. Wood, Relation of strength of wood to duration of load, R1916, United States Department 522 of Agriculture, Forest service, 1951.

523 [22] B.R. Ellingwood, D. Rosowsky "Duration of Load Effects in LRFD for Wood Construction", 524 ASCE Journal of Structural Engineering, 117, 584-599, 1991.

525 [23] L. Pham "Load combinations and probabilistic load models for limit state codes", Institution of 526 Engineers, Australia, Civil Engineering Transactions, 27, 62-67, 1985.

527 [24] P.L. Chalk, R.B. Corotis "Probability model for design live loads", ASCE Journal of Structural 528 Engineering, ST10, 2017-2033, 1980.

529 [25] E.M. Hendrickson, B.R. Ellingwood, J. Murphy "Limit State Probabilities for Wood Structural 530 Members", ASCE Journal of Structural Engineering, 113, 88-106, 1987.

531 [26] J. Köhler, J.D. Sørensen "Probabilistic representation of duration of load effects in timber 532 structures", Engineering Structures, 33, 462-467, 2011.

533 [27] JCSS, JCSS Probabilistic model code, Part 2: Load models, 2001.

534 [28] CIB Report, Actions on structures live loads in buildings, Publication 116, 1989.

535 [29] D.V. Rosowsky, W.M. Bulleit "Load duration effects in wood members and connections: order 536 statistics and critical loads", Structural Safety, 24, 347-362, 2002. 
[30] EN 1995-1-1, Eurocode 5: Design of timber structures - Part 1-1: General - Common rules and rules for buildings The European Union Per Regulation, Brussel, Belgium, 2004.

[31] L. Pham "Reliability analysis of Australian structural standards - Report to the Association of Consulting Structural Engineers of NSW", Non published, 2007.

[32] B.R. Ellingwood, Y. Li "Counteracting Structural Loads: Treatment in ASCE Standard 7-05", Journal of Structural Engineering, 135, 94-97, 2009.

[33] AS/NZS 1170.2, Structural design actions - Wind actions, Standards Australia, Sydney, Australia, 2011.

[34] C.C. Gerhards "Time-related effects on wood strength: a linear cumulative damage theory", Wood Science and Technology, 11, 139-144, 1979.

[35] C.C. Gerhards, C.L. Link "A cumulative damage model to predict load duration characteristics of lumber", Wood and fibre science, 19, 147-164, 1987.

[36] J.D. Barrett, R.O. Foschi "Duration of load and probability of failure in wood. Part 1: modelling creep rupture", Canadian Journal of Civil Engineering, 5, 505-514, 1978.

[37] R.O. Foschi, B.R. Folz, F.Z. Yao, Reliability-based design of wood structures, Structural research series, Rep. no. 34, Vancouver, Canada, 1989.

[38] J.D. Sørensen, S. Svensson, B.D. Stang "Reliability-based calibration of load duration factors for timber structures", Structural Safety, 27, 153-169, 2005.

[39] Z. Cai, D.V. Rosowsky, M.O. Hunt, K.J. Fridley "Comparison of actual vs. simulated failure distributions of flexural wood specimens subject to 5-day load sequences", Forest Products Journal, $50,74-80,2000$.

[40] AS/NZS 4357.2, Structural laminated veneer lumber, Part 2: Determination of structural properties - Test methods, Standards Australia, Sydney, Australia, 2006.

[41] ASTM D3500-14, Standard Test Methods for Structural Panels in Tension, ASTM International, Pennsylvania, USA, 2014. 
[42] D. Rosowsky, B.R. Ellingwood "Reliability of wood systems subjected to stochastic live loads", 563 Wood and fibre science, 24, 47-59, 1992.

564 [43] P. Hoffmeyer, J.D. Sørensen "Duration of load revisited", Wood Science and Technology, 41, $565 \quad 687-711,2007$.

566 [44] A. Hanhijärvi, P. Galimard, P. Hoffmeyer "Duration of load behaviour of different sized straight 567 timber beams subjected to bending in variable climate", Holz als Roh- und Werkstoff, 56, 285-293, 5681998.

569 [45] D.G. Hunt "A Unified Approach to Creep of Wood", Proceedings: Mathematical, Physical and $570 \quad$ Engineering Sciences, 455, 4077-4095, 1991.

571 [46] A. Martensson "Mechano-sorptive effects in wooden material", Wood Science and Technology, $572 \quad 28,437-449,1994$.

573 [47] ANSI/AF\&PA NDS-2005, National design specification for wood construction and Supplement, 574 American Forest and Paper Association, 2005.

575 [48] Wesbeam, FAQ on LVL, https://wesbeam.com/about-us/faq, Acessed on 17/02/2016

576 [49] AS/NZS 4357.0, Structural laminated veneer lumber, Part 0: Specifications, Standards Australia, 577 Sydney, Australia, 2005.

578 [50] B.R. Ellingwood, J.G. MacGregor, T.V. Galambos, C.A. Cornell "Probability based load criteria: 579 load factors and load combinations", Journal of the Structural Division, 108, 978-997, 1982.

580 [51] D. Rosowsky, D.S. Gromala, P. Line "Reliability-based code calibration for design of wood 581 members using load and resistance factor design", Journal of Structural Engineering, 131, 338-344, 5822005.

583 [52] B.R. Ellingwood, T.V. Galambos, J.G. MacGregor, C.A. Cornell, Development of a probability 584 based load criterion for American National Standard A58 - Building code requirement for minimum 585 design loads in buidlings and other structures, Washington D.C., U.S.A., 1980. 
586 [53] B.R. Ellingwood, D.V. Rosowsky, Y. Li, J.H. Kim "Fragility Assessment of Light-Frame Wood 587 Construction Subjected to Wind and Earthquake Hazards", ASCE Journal of Structural Engineering, 588 130, 1921-1930, 2004.

589 [54] A.S. Nowak, K.R. Collins, Reliability of structures, second edition, (CRC Press), New York, 590 U.S.A., 2013.

591 [55] AS 5104, General principles on reliability for structures, Standards Australia, Sydney, Australia, 5922005.

593 [56] B.R. Ellingwood, P.B. Tekie "Wind Load Statistics for Probability-Based Structural Design", 594 Journal of Structural Engineering, 125, 453-463, 1999.

595 [57] ANSI/AWC NDS, National design specification (NDS) for wood construction, American Wood 596 Council, Leesburg, U.S.A., 2015. 
Table 1: Coefficients $a$ and $b$ in the Gerhards' $[34,35]$ model reported in the literature

\begin{tabular}{|c|c|c|}
\hline Reference & Timber & Coefficients \\
\hline Hoffmeyer, et al. [43] & $\begin{array}{l}\text { Norway Spurce at } 55 \% \text { rela- } \\
\text { tive humidity }\end{array}$ & $\begin{array}{l}a=31.580 \ln (\text { day }) \\
b=36.549\end{array}$ \\
\hline Gerhards, et al. [35] & $\begin{array}{l}\text { Douglas fir at } 22.8^{\circ} \mathrm{C} \text { and } \\
50 \% \text { relative humidity }\end{array}$ & $\begin{array}{l}\text { For all loading types } \\
a=17.341 \text { to } 39.406 \ln \text { (day) } \\
b=21.038 \text { to } 47.700 \\
\text { For constant loading } \\
a=17.341 \text { to } 23.927 \ln \text { (day) } \\
b=21.037 \text { to } 29.619\end{array}$ \\
\hline
\end{tabular}

601

602

603

604

605

Table 2: Proposed capacity factors $\phi$ for the LVL beams manufactured from early to mid-rotation hardwood plantation logs (Governing load combination showed in bracket)

\begin{tabular}{lccc}
\hline Product & $\begin{array}{c}\text { Category 1 } \\
\text { Houses and secondary } \\
\text { structures }\end{array}$ & $\begin{array}{c}\text { Category 2 } \\
\text { Primary structures } \\
\text { other than houses }\end{array}$ & $\begin{array}{c}\text { Category 3 } \\
\text { intended to full and } \\
\text { essential service or } \\
\text { post disaster function }\end{array}$ \\
\hline LVL in AS 1720.1 [18] & 0.95 & 0.90 & 0.80 \\
Proposed LVL - Edge bending & 0.85 (LC4) & 0.85 (LC4) & 0.80 (LC2 \& LC4) \\
Proposed LVL - Flat bending & 0.85 (LC4) & 0.80 (LC2) & 0.70 (LC2) \\
\hline
\end{tabular}

606

607 


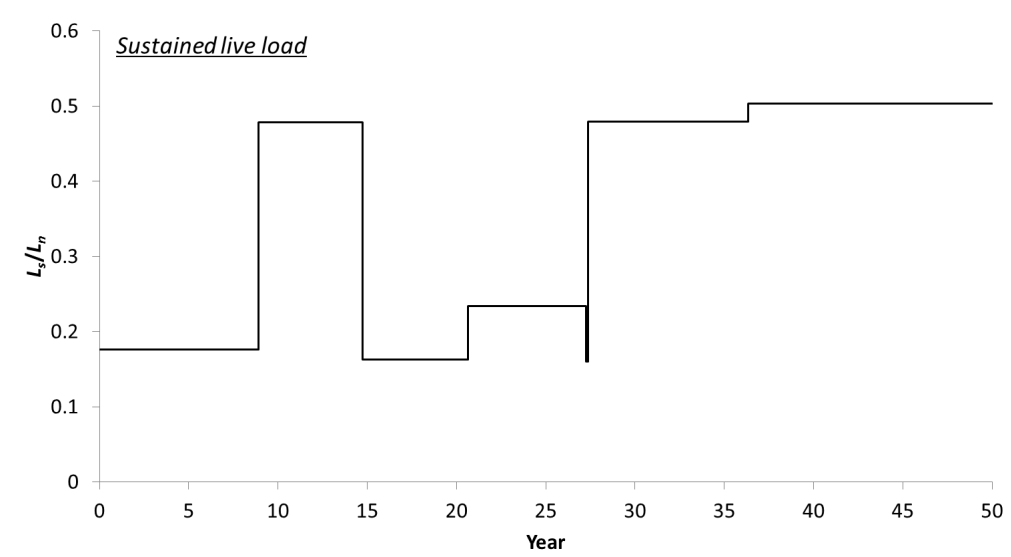

(a)

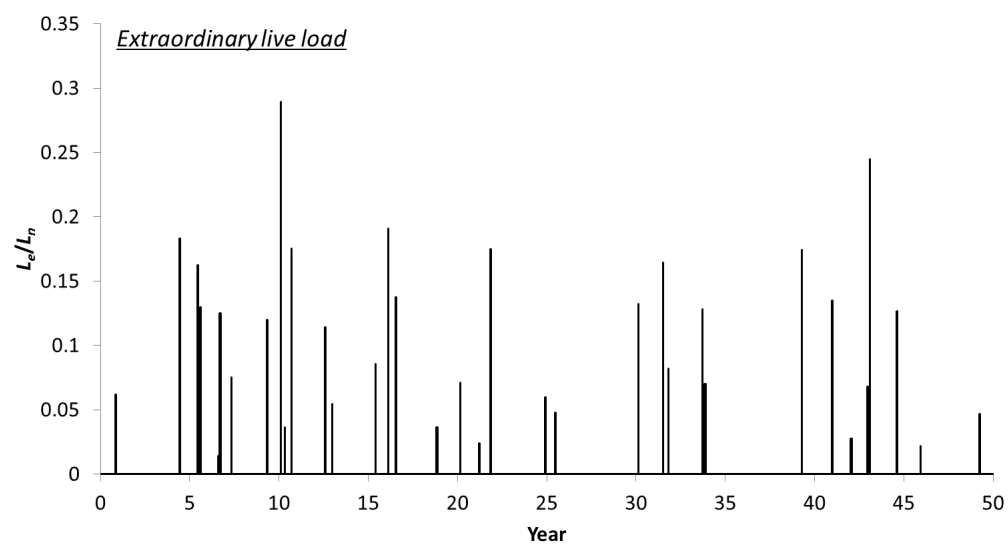

(b)

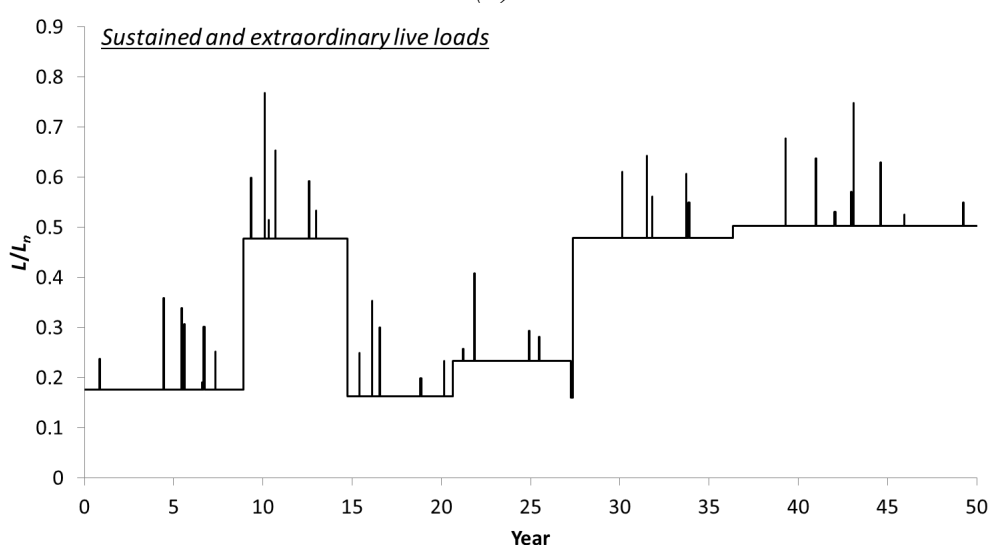

(c)

612

614

615

616

Figure 1: Example of a stochastic live load used in this study over a 50 years period (a) Sustained live load, (b) Extraordinary live load and (c) combined Sustained and Extraordinary live loads
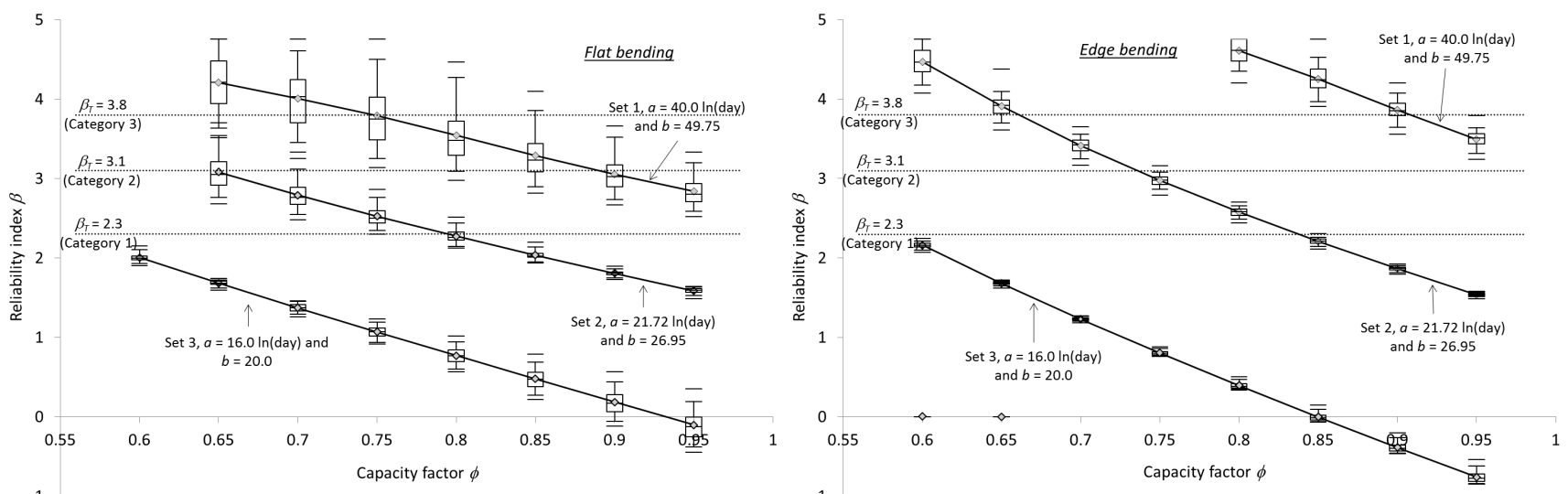
Figure 2: Variation in reliability index $\beta$ versus capacity factor $\phi$ for LCl and (a) flat bending and (b) edge

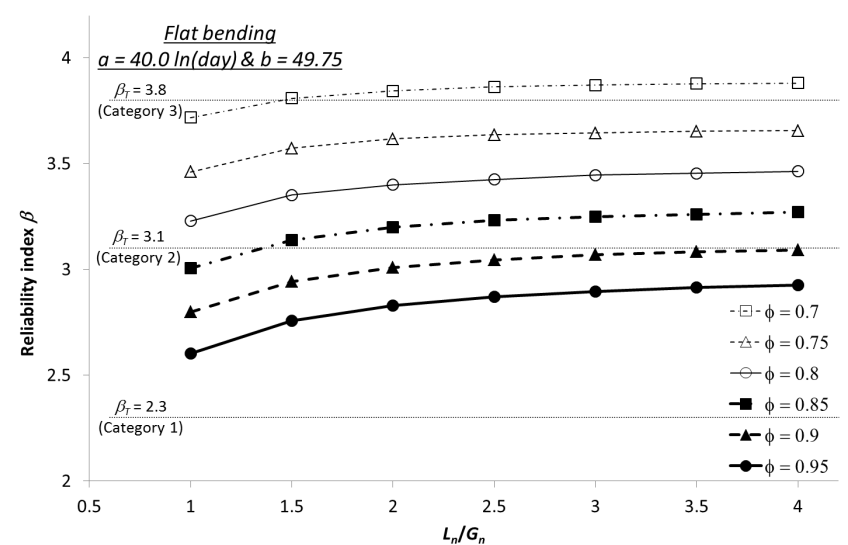

(a)

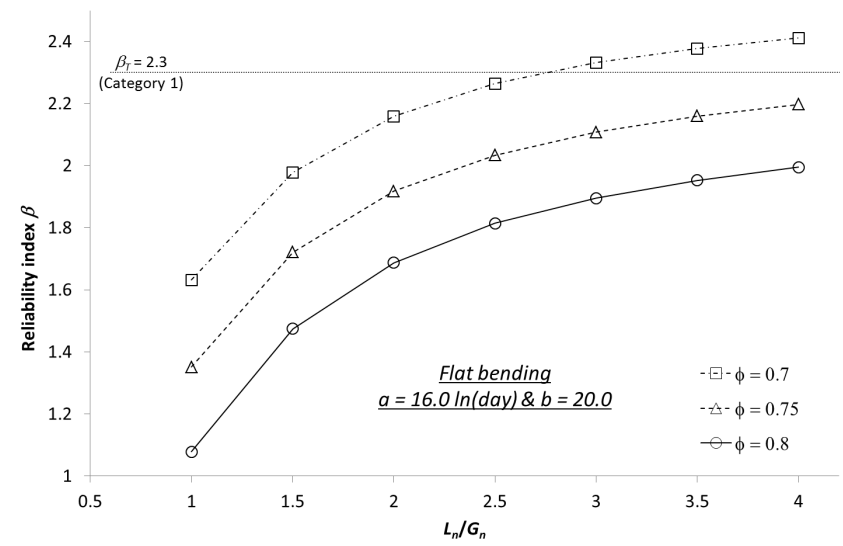

(c)

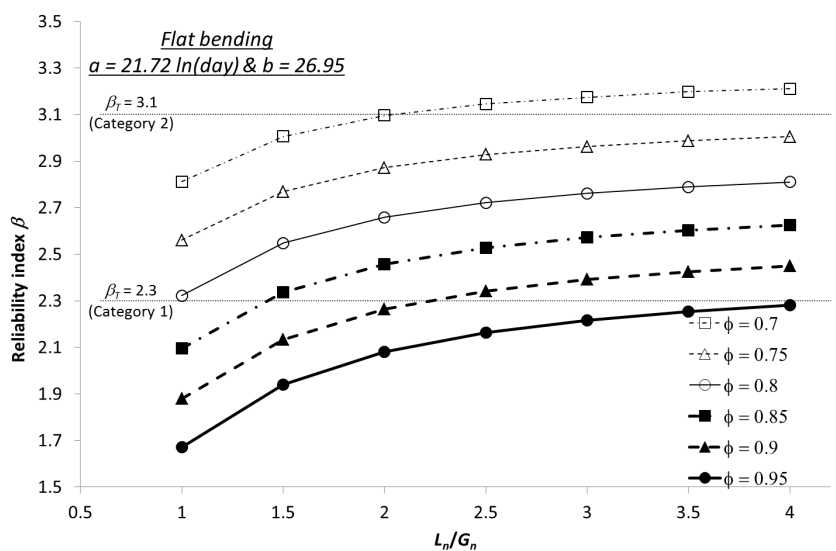

(b)



(d)

Figure 3: Variation in reliability index $\beta$ versus capacity factor $\phi$ and $L_{n} / G_{n}$ ratios for $L C 2$ and flat bending, (a) damage Set 1, (b) damage Set 2, (c) damage Set 3 and (c) selected curves with box plots for damage Set 1 
631

632

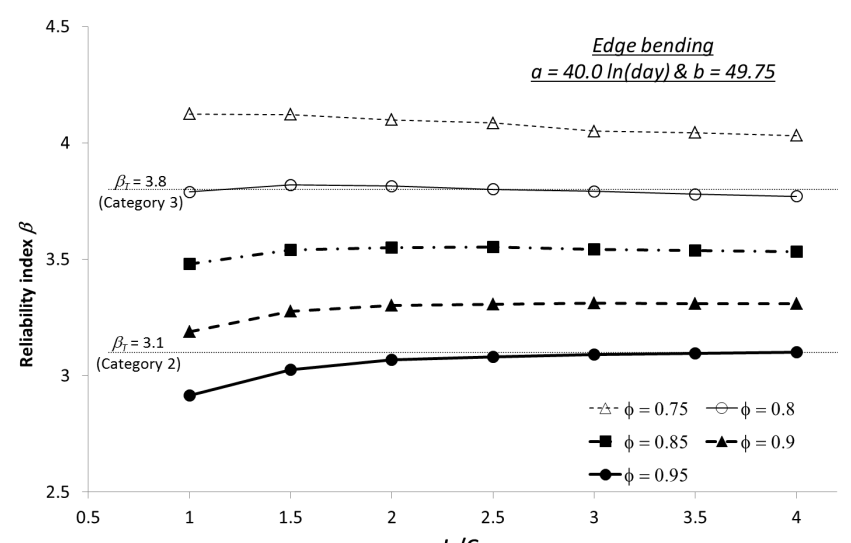

(a)

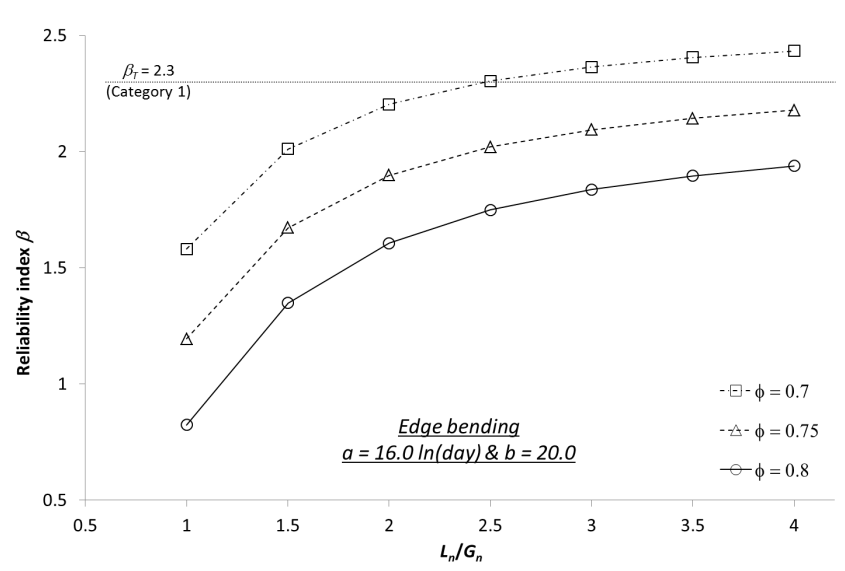

(c)

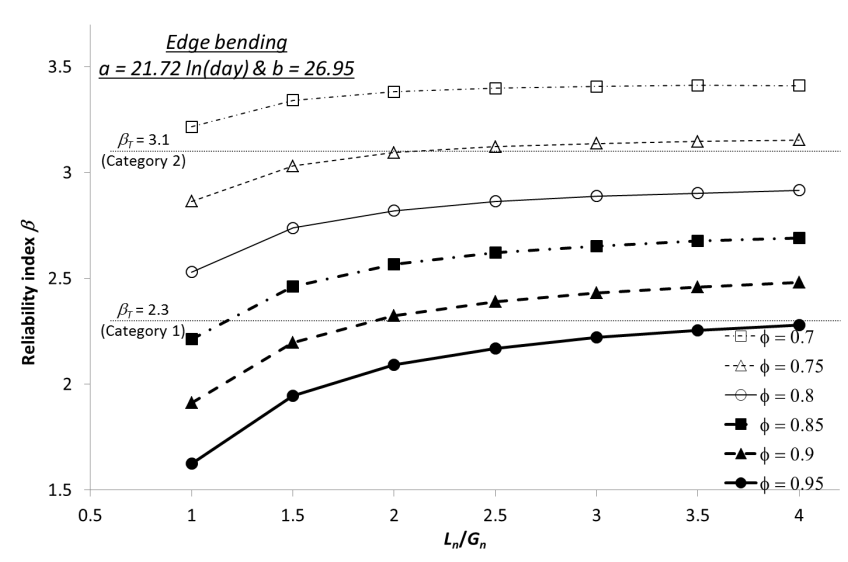

(b)

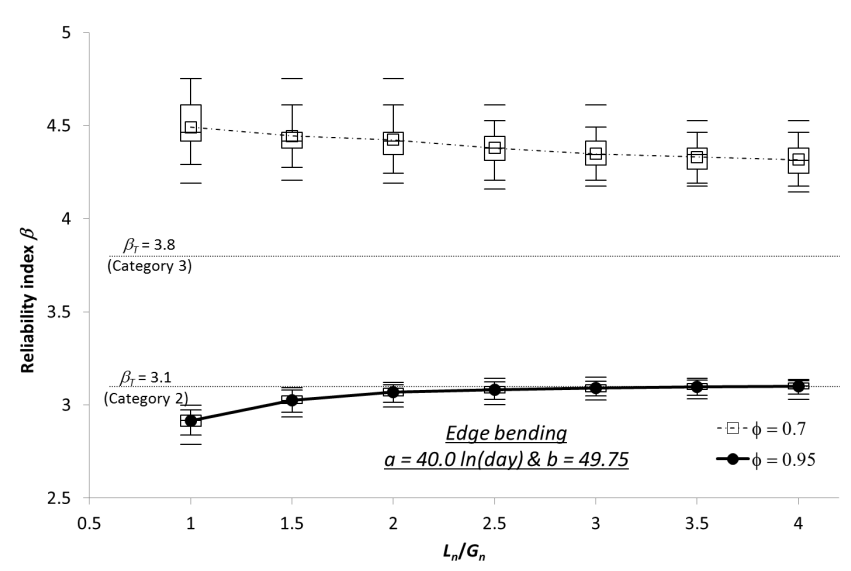

(d)

Figure 4: Variation in reliability index $\beta$ versus capacity factor $\phi$ and $L_{n} / G_{n}$ ratios for $L C 2$ and edge bending, 636 (a) damage Set 1, (b) damage Set 2, (c) damage Set 3 and (c) selected curves with box plots for damage Set1 


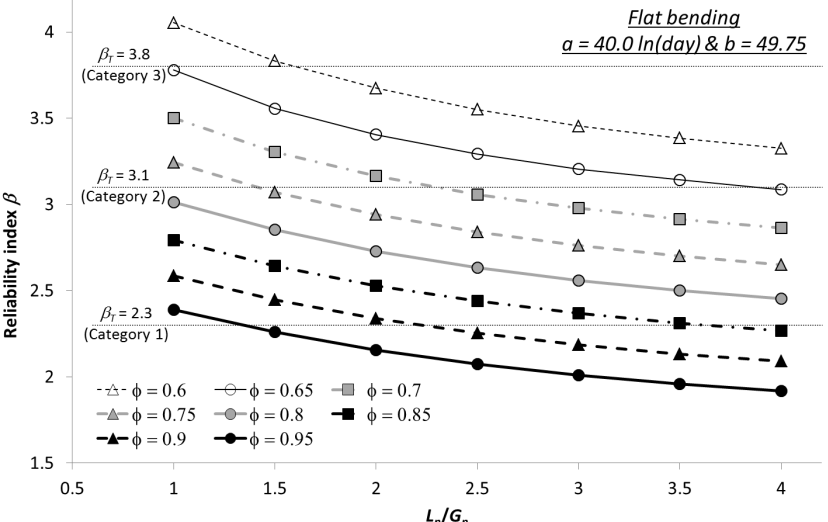

(a)

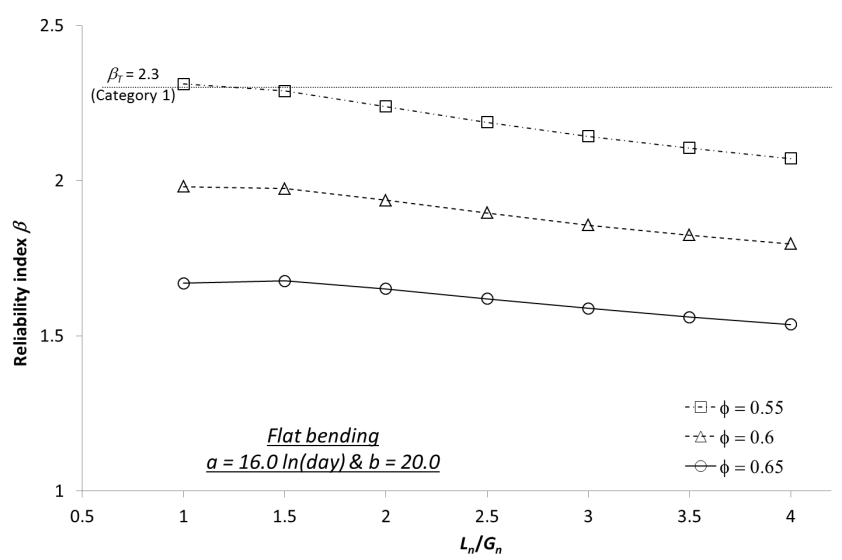

642

643

644

645

646

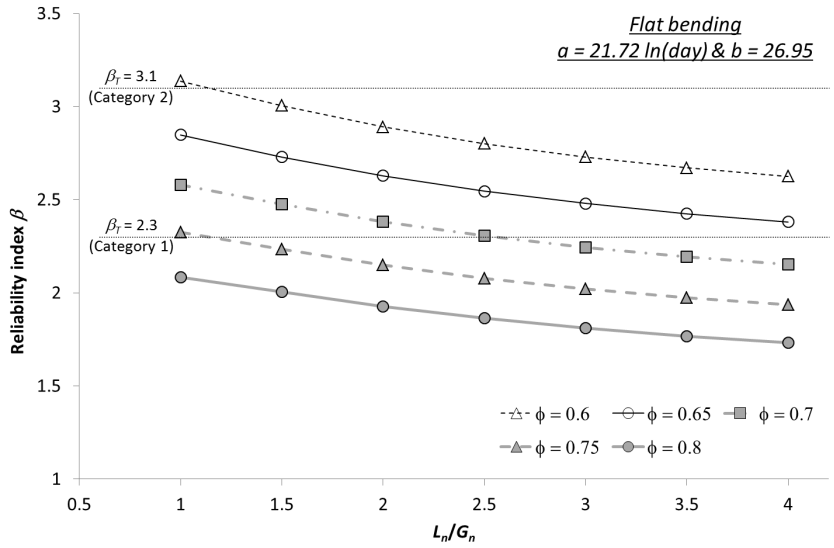

(b)

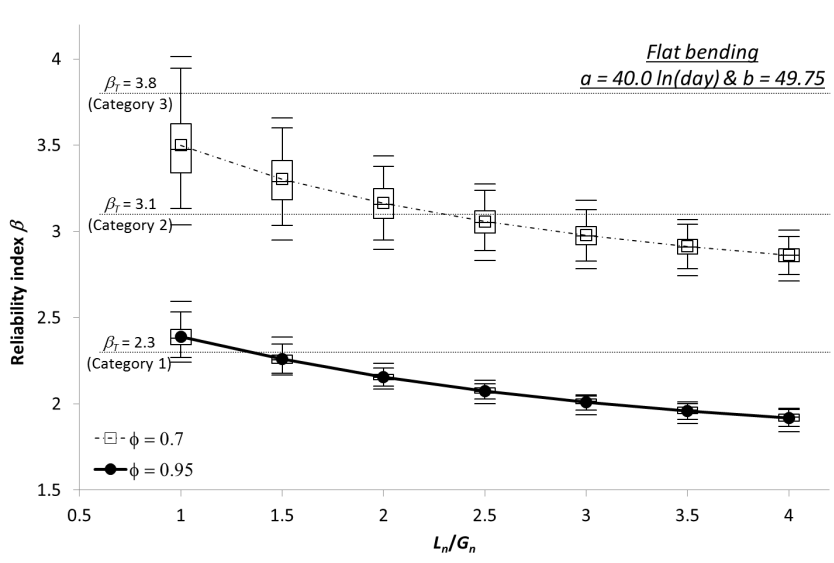

(d)

Figure 5: Variation in reliability index $\beta$ versus capacity factor $\phi$ and $L_{n} / G_{n}$ ratios for $L C 3$ and flat bending, (a) damage Set 1, (b) damage Set 2, (c) damage Set 3 and (c) selected curves with box plots for damage Set1 


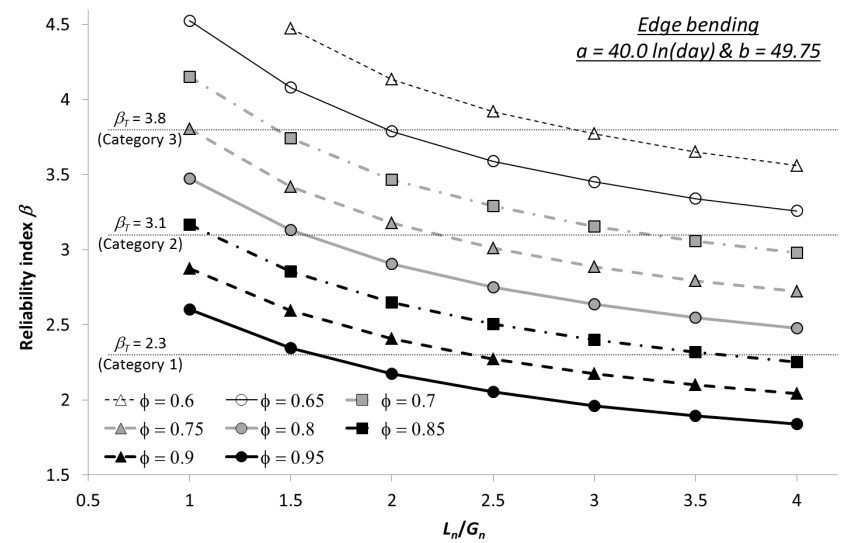

(a)

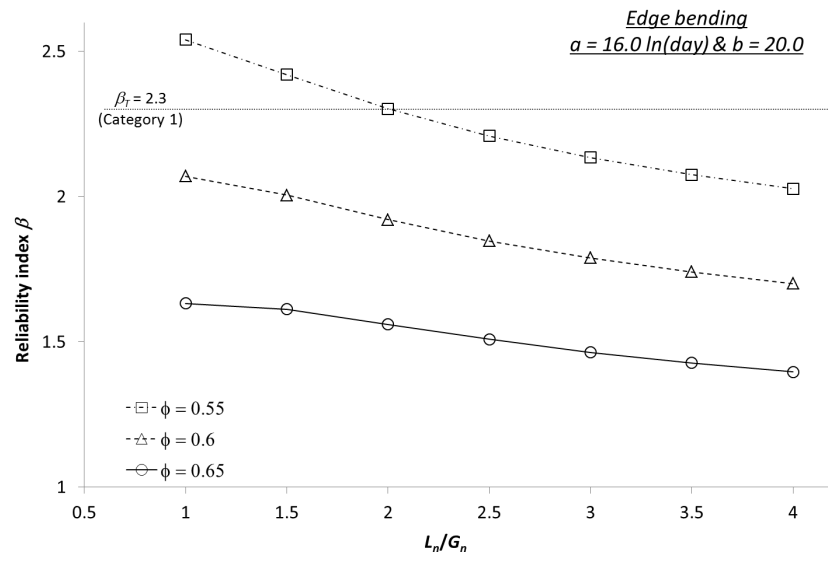

(c)

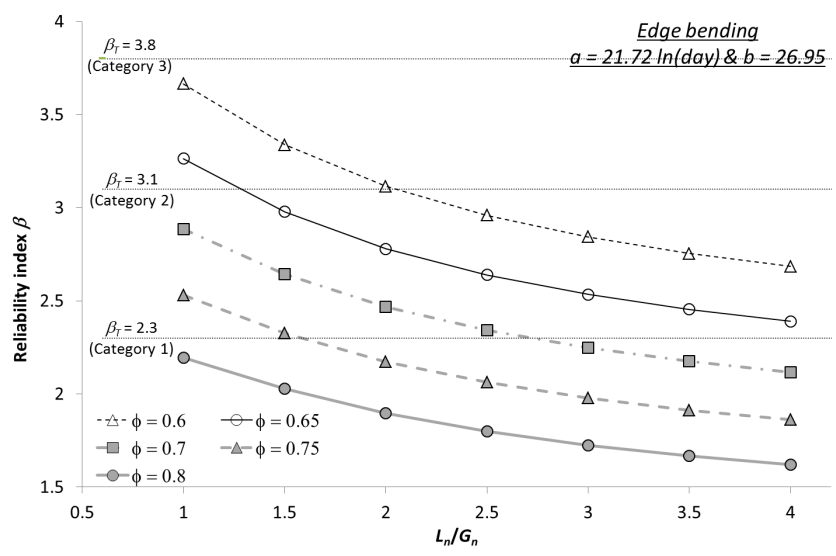

(b)

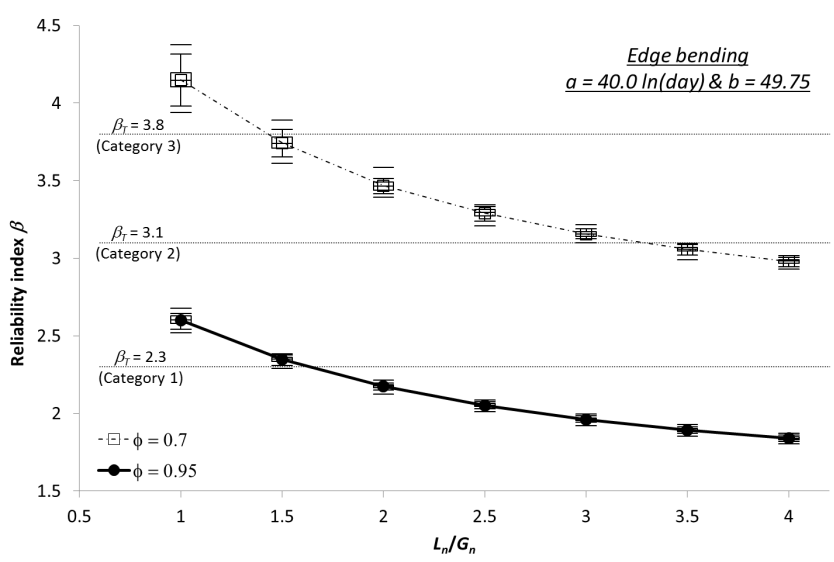

(d)

Figure 6: Variation in reliability index $\beta$ versus capacity factor $\phi$ and $L_{n} / G_{n}$ ratios for $L C 3$ and edge bending, 652 (a) damage Set 1, (b) damage Set 2, (c) damage Set 3 and (c) selected curves with box plots for damage Set1 
655

656

661

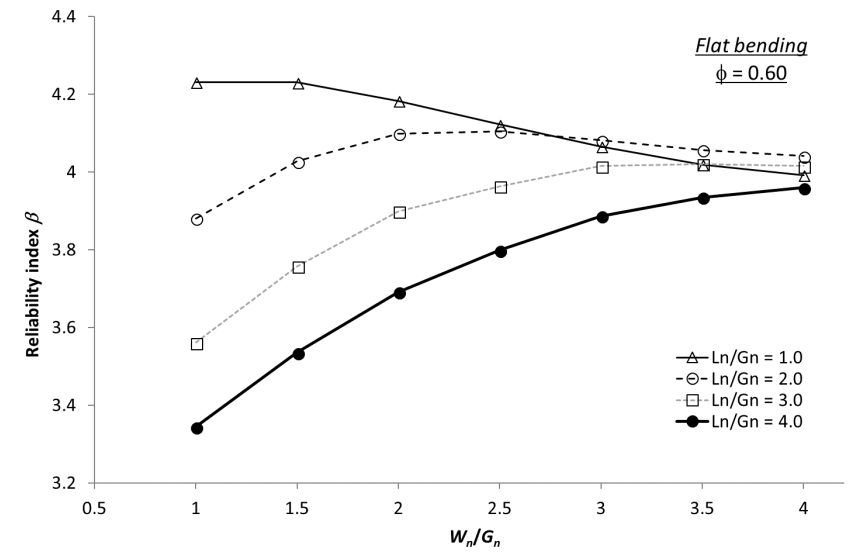

(a)

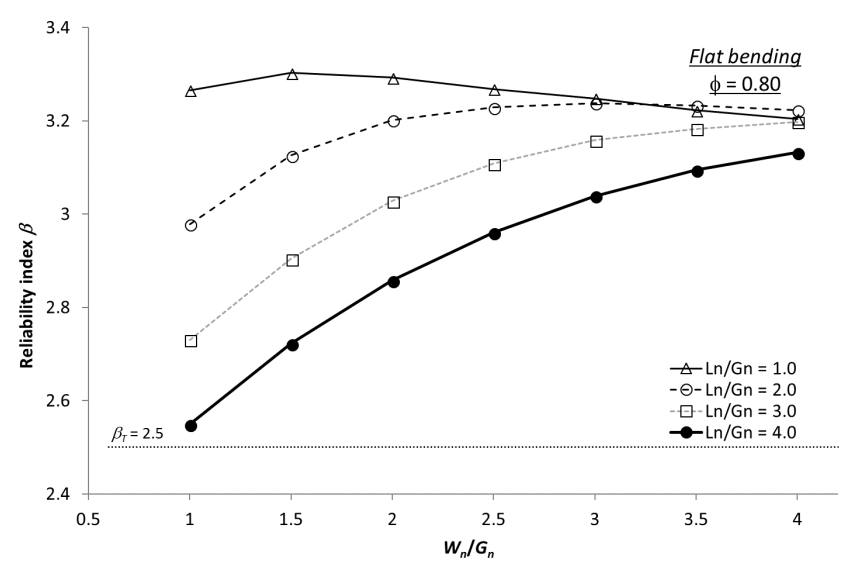

(c)

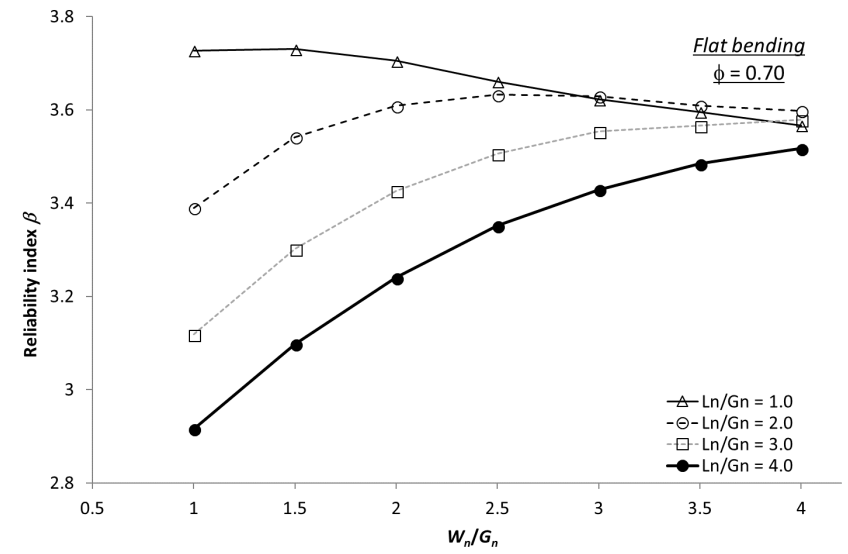

(b)

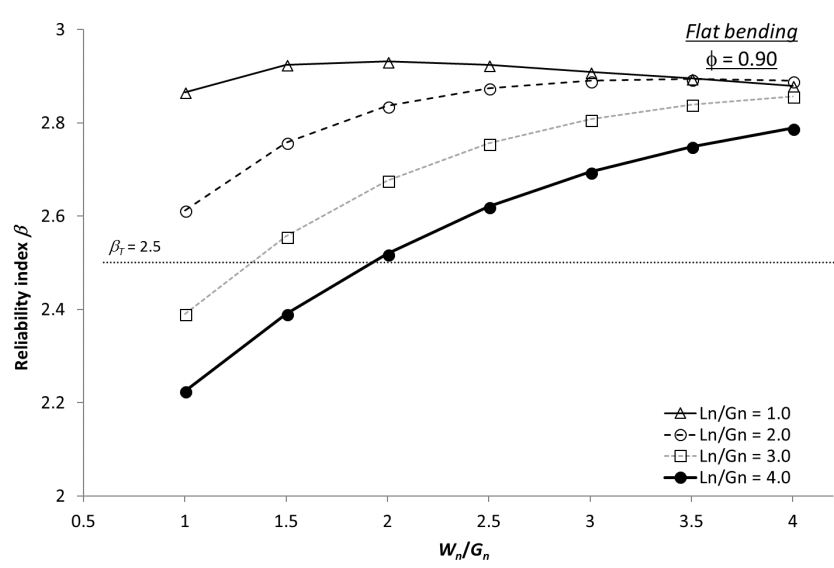

(d)

Figure 7: Variation in reliability index $\beta$ versus $L_{n} / G_{n}$ and $W_{n} / G_{n}$ ratios for $L C 4$ for selected cases and flat bending (a) $\phi=0.60$, (b) $\phi=0.70$, (c) $\phi=0.80$, and (d) $\phi=0.90$ 
663

664

665

666

667

668

669

670

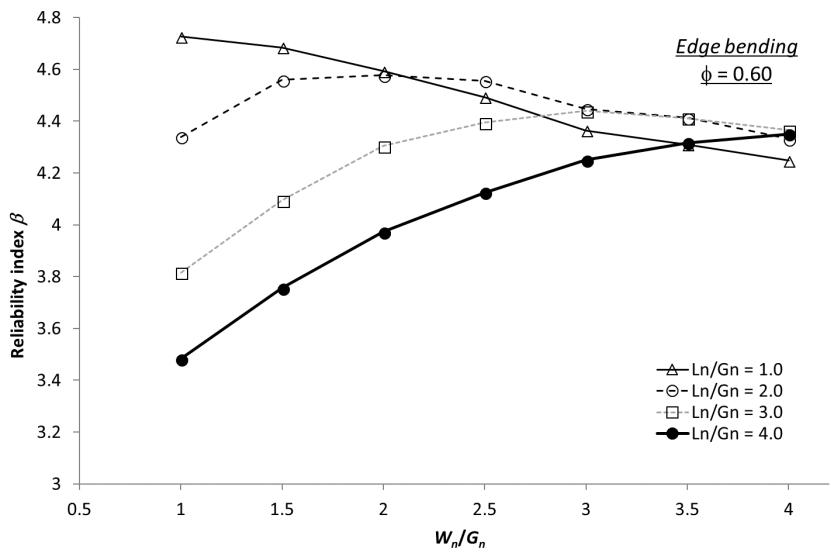

(a)

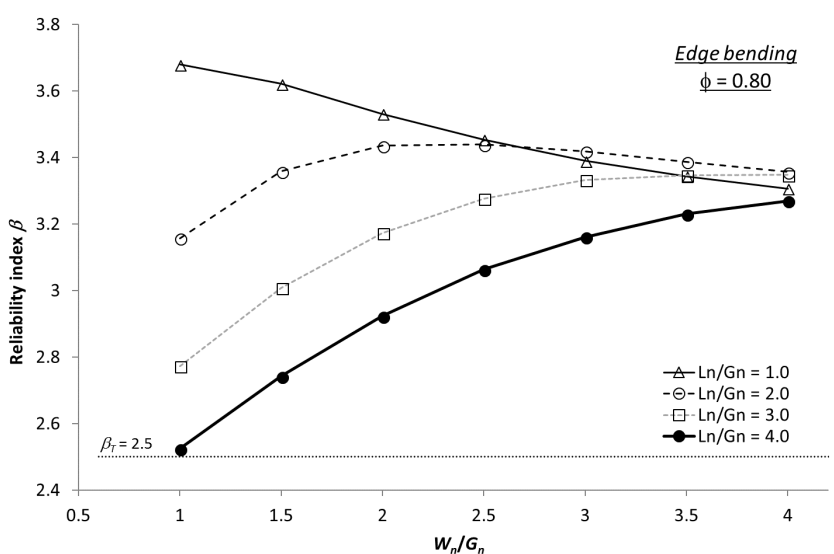

(c)

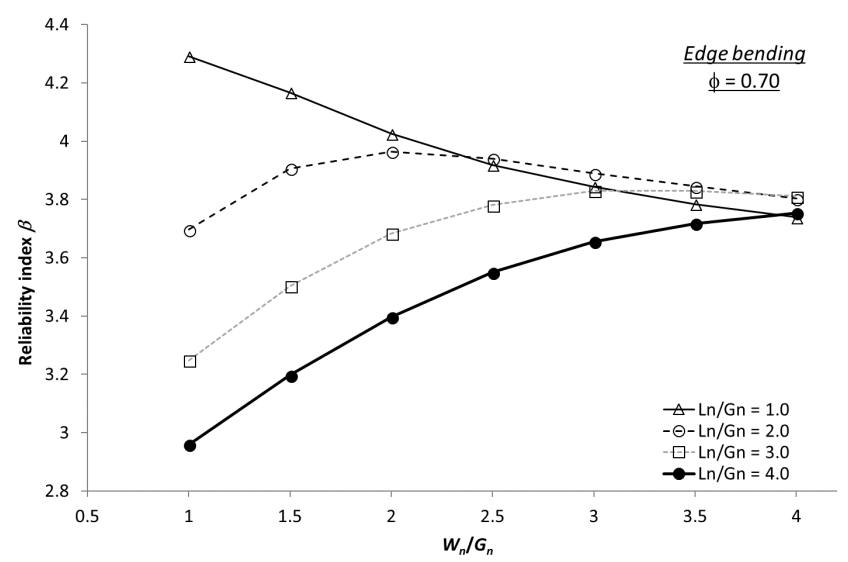

(b)

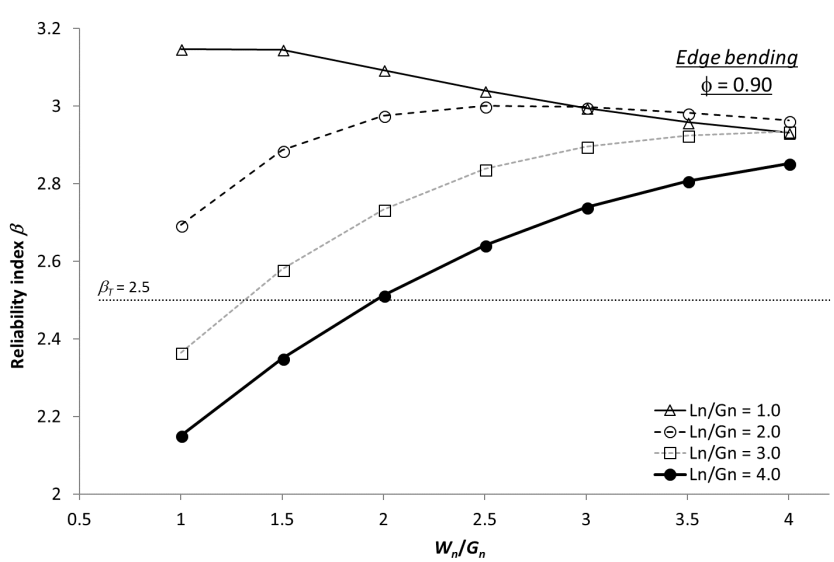

(d)

Figure 8: Variation in reliability index $\beta$ versus $L_{n} / G_{n}$ and $W_{n} / G_{n}$ ratios for $L C 4$ for selected cases and edge bending (a) $\phi=0.60$, (b) $\phi=0.70$, (c) $\phi=0.80$, and (d) $\phi=0.90$ 
671

672

673

674

675

676

677

678

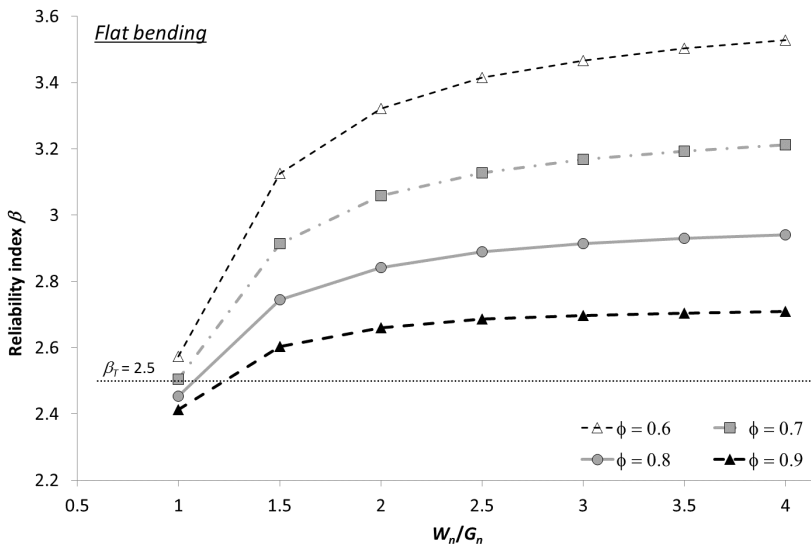

(a)

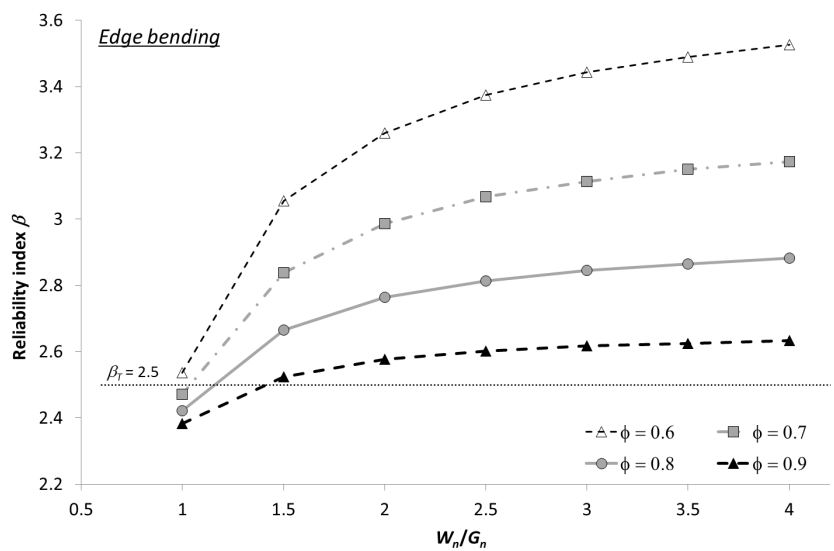

(b)

Figure 9: Variation in reliability index $\beta$ versus selected capacity factor $\phi$ and $W_{n} / G_{n}$ ratios for $L C 5$ for (a) flat bending and (b) edge bending 